\title{
APLIKASI TUTORIAL MEMASAK MASAKAN KHAS SUMBAWA MENGGUNAKAN AUGMENTED RELITY BERBASIS ANDROID
}

\author{
Heryan Saputra Ademula \\ Program Studi Teknik Informatika S1, Fakultas Teknologi Industri \\ Institut Teknologi Nasional Malang, Jalan Raya Karanglo km 2 Malang, Indonesia \\ heryansaputra36@gmail.com
}

\begin{abstract}
ABSTRAK
Pemanfaatan teknologi informasi (TI) dalam proses penyampaian informasi mengalami perkembangan pesat. Saat ini teknologi terbaru yang di pakai untuk menyampaikan informasi adalah teknologi Augmented Reality (AR), pada teknologi AR pengguna dapat memvisualisasikan object dalam bentuk 3 dimensi. AR sendiri memiliki banyak kelebihan di bidang bersifat interaktif sehingga AR banyak di implementasikan ke berbagai bidang. Di dunia pendidikan AR banyak di gunakan untuk memperkenalkan berbagai macam benda seperti makanan, bangunan,budaya,dan alat musik. Salah satu contoh resep masakan Indonesia karena memiliki rasa yang berbeda-beda dan berbagai macam jenis makanan dari setiap daerah salah satunya masakan sumbawa. Tujuan dari penelian ini adalah untuk lebih mengenalkan tentang masakan Sumbawa dan cara memasaknya.

Berdasarkan hasil review dari berbagai jurnal dan buku tentang penelitian AR, diperoleh kesimpulan bahwa AR dapat dipakai untuk lebih interaktif memperkenalkan dalam memperkenalkan masakan khas sumbawa. Maka dari itu penulis akan mengembangkan sebuah aplikasi tutorial memasak masakan khas sumbawa menggunakan Augmented Reality berbasis android. Metode yang digunakan bias menggunakan metode Marker Based Tracking dan Markless AR
\end{abstract}

Kata kunci : Augmented Reality, Resep Masakan, 3 Dimensi,Marker Based Tracking

\section{PENDAHULUAN}

\subsection{Latar Belakang}

Teknologi merupakan sebuah terobosan baru yang dapat membantu seseorang dalam melakukan pekerjaan sehari-hari. Perkembangan tekhnologi saat ini seirama dengan perkembangan zaman yang semakin modern membuat tekhnologi menjadi semakin berkembang.

Di sisi lain banyak orang yang belum mengetahui apa itu masakan Sumbawa dan resep makanan khas Sumbawa. Aplikasi ini sebagai media untuk memperkenalkan masakan khas sumbawa seperti layaknya maskan Padang yang sudah terkenal di Indonesia. Banyak media yang dapat digunakan untuk menyalurkan hobi memasak terutama masakan khas Sumbawa.Salah satu medianya adalah android,penulis aka membuat Aplikasi Resep Masakan Khas Sumbawa guna memenuhi kebutuhn informasi, khususnya perantau dari sumbawa yang kadang mereka rindu dengan masakan khas sumbawa.

Salah satu metode yang dapat di gunakan adalah Augmented Reality karena Augment Reality dapat menampilkan animasi berbentuk 3D dari semua sisi agar dapat membuat para pengguna merasa tertarik untuk lebih mempelajari tentang masakan sumbawa itusendiri. Perkembangan teknologi pada zaman ini telah mampu menciptakan suatu teknologi baru yaitu smartphone, selain alat komunikasi smartphone juga mudah diakses kapan saja dan dilengkapi dengan berbagai fitur-fitur menarik lainnya. Antara lain dapat membaca objek 3D dari metode Augmented Reality itu sendiri.

Berdasarkan uraian di atas maka penulis melakukan pengembangan suatu perangkat lunak yang berjudul "APLIKASI TUTORIAL MEMASAK MASAKAN KHAS SUMBAWA MENGGUNAKAN AUGMENTED REALITY BERBASIS ANDROID" yang diharapkan dapat membantu memberikan informasi tentang macam-macam rumah adat indonesia bagi pengguna.

\subsection{Rumusan Masalah}

Dari latar belakang tersebut maka dicari suatu pemecah masalah yaitu :

1. Bagaimana cara merancang dan mengimplementasikan Augmented Reality pada aplikasi tutorial memasak masakan khas sumbawa menggunakan Augmented Reality berbasis android?

2. Bagaimana membangun aplikasi mobile yang bergerak dalam bidang kuliner.

3. Bagaimana cara sistem dapat mengenali marker menggunakan smartphone berbasis android ? 
4. Bagaimana merancang aplikasi yang efisien dan bisa memenuhi kebutuhan pengguna.

\subsection{Batasan Masalah}

Dalam penyusunan agar sistematis dan mudah dimengerti, maka akan diterapkan beberapa batasan masalah :

1. Aplikasi ini di jalankan dengan bantuan kamera smartphone Android.

2. Aplikasi ini di buat dengan menggunakan software Unity3D, Vuforia, dan Android SDK.

3. Object 3D dibuat menggunakan software google Sketchup.

4. Objek 3D yang ditampilkan berupa masakan khas Sumbawa.

\subsection{Tujuan}

Ditinjau dari latar belakang tersebut diatas maka, tujuan penulisan skripsi ini :

1. Diharapkan aplikasi ini dapat memberikan informasi resep-resep masakan Khas Sumbawa pada anak remaja khususnya ibu - ibu yang hobi memasak.

2. Diharapkan dapat menjadi acuan, referensi, dan dapat memberikan informasi serta cara membuat masakan Khas Sumbawa bagi mereka yang hobi masak dan khususnya bagi perantau dari sumbawa yang rindu dengan masakan Khas Sumbawa.

3. Menambah wawasan masyarakat tentang kegunaan teknologi.

\section{TINJAUAN PUSTAKA}

\subsection{Resep Masakan}

Resep masakan bahan atau cara yang digunakan untuk membuat masakan yang telah teruji ke akuratannya. Selain menyiapkan bahan, dalam resep masakan juga tersedia keterangan dan panduan seputar cara menyajikan hasil masakan tersebut. Masakan Sumbawa secara umum super pedas dan sangat berbumbu, menyebabkan porsi nasi dalam makanan menjadi cukup banyak. Pada umumnya resep asli masakan Sumbawa menggunakan banyak terasi,garam dan lombo (cabe rawit ). Pada dasarnya terdapat dua jenis bumbu dasar masakan utama Sumbawa yaitu sepat,singang dan padu telu.

a. Singang

Singang adalah masakan berkuah yang rasanya asam dan manis. Ada juga sejenis masakan singang yang tidak berkuah yang dinamakan singang toar.Apabila menyajikan singang tidak perlu menyajikan sayur karena singang itu sendiri berfungsi sebagai sayur lebih-lebih kalau di dalam singang sudah dicampur bahan sayur seperti : terong, daun turi , buah randu muda.

\section{b. Padu Telu}

Masakan ini disebut dengan padu telu karena padu telu (=tiga sudut). Karena benbentuk segetiga. Masakan ini juga termasuk masakan istimewa karena sering disajikan pada acara-acara istimewa. Dan rasanya sangat mengundang selera.

\subsection{Augmented Realit}

Definisi Augmented Reality atau realitas bertambah sebagai penggabungan benda-benda nyata dan maya di lingkungan nyata. Hasilnya ditampilkan secara interaktif dan dalam waktu nyata (realtime). Ada beberapa metode yang digunakan pada Augmented Reality yaitu marker based tracking dan markerless. Berikut ini merupakan beberapa teknik dalam metode markerless object tracking:

1. Marker Based Tracking

2. Markerless

3. Face Tracking

4. 3D Object Tracking

5. Motion Tracking

6. GPS Based Tracking Augmented reality.

Teknologi AR ini dapat menyisipkan suatu informasi tertentu ke dalam dunia maya dan menampilkannya di dunia nyata dengan bantuan perlengkapan seperti webcam, komputer, Smartphone, maupun kacamata khusus. User ataupun pengguna didalam dunia nyata tidak dapat melihat objek maya dengan mata telanjang, untuk mengidentifikasi objek dibutuhkan perantara berupa komputer dan kamera yang nantinya akan menyisipkan objek maya ke dalam dunia nyata [1].

\subsection{Android}

Sistem operasi yang berbasis Linux untuk telepon seluler seperti telepon pintar dan komputer tablet. Android menyediakan platform terbuka bagi para pengembang untuk menciptakan aplikasi mereka sendiri untuk digunakan oleh bermacam peranti bergerak. Awalnya Google Inc. membeli Android Inc pendatang baru yang membuat peranti lunak untuk ponsel. Kemudian untuk mengembangkan Android, dibentuklah Open Handset Alliance, konsorsium dari 34 perusahaan peranti keras, peranti lunak, dan telekomunikasi, termasuk Google, HTC, Intel, Motorola, Qualcomm, TMobile, dan Nvidia.

\subsection{Vuforia}

Vuforia adalah Augmented Reality Software Development Kit (SDK) untuk perangkat mobile yang memungkinkan pembuatan aplikasi Augmented Reality. SDK ini menggunakan teknologi computer vision untuk mengenali dan 
melacak gambar planar (Gambar Target) dan objek 3D sederhana, seperti kotak, secara realtime. Kemampuan vuforia yang dapat merubah kertas dengan latar kosong menjadi tampilan dengan grafis 3D yang menarik, karena adanya teknologi Augmented Reality. Dengan vuforia, developer dapat memaksimalkan kemampuan teknologi Augmented Reality untuk menciptakan konten seperti, aplikasi, game, iklan dan presentasi.

\subsection{Image Target}

Image Target adalah gambar yang bisa dilacak dan dideteksi oleh Vuforia SDK. Vuforia SDK mengaplikasikan algoritma khusus untuk mendeteksi dan melacak fitur yang secara natural ditemukan didalam sebuah gambar. Vuforia SDK mengenali image target dengan membandingkan fitur yang ada pada gambar fisik dengan gambar yang ada didalam database aplikasi. Ketika gambar terdeteksi, SDK akan melacak gambar selama berada di sudut pandang kamera. Fitur yang dilacak oleh Vuforia SDK adalah detail berbentuk sudut pada gambar. Gambar yang akan digunakan sebagai image target harus memiliki beberapa kriteria pembuatan image target yaitu:

a. Memiliki format 8 atau 16-bit dan JPG atau PNG.

b. Gambar berformat JPG harus memiliki warna RGB atau grayscale

c. Memiliki resolusi minimal 320 pixel.

d. Memiliki ukuran maksimal 2 MB.

e. Gambar tidak memiliki pola yang berulang. Setelah diunggah, secara otomatis gambar akan mendapat implementasi algoritma yang dibuat khusus oleh vuforia sehingga fitur-fitur bisa terlihat dengan jelas. [1]

\subsection{Analisis Sistem}

Tahap analisis sistem ini akan menganalisis mulai dari tahap awal pembuatan aplikasi.

a. Analisis Masalah

Aplikasi ini akan membuat sebuah tutorial memasak masakan Sumbawa. Dengan bantuan augmented reality, pengguna akan dimanjakan dengan macam-macam masakan kas Sumbawa berbentuk visual 3D yang ada di smartphone, agar para pengguna mengetahui seperti apakah masakan khas Sumbawa tanpa harus datang ke sumbawa ataupun mencarinya di internet yang hanya tampak 2D saja.

b. Analisis Kebutuhan

Dalam perancangan aplikasi, data yang akan diolah adalah merupakan gambar beserta informasi. Data ini memiliki peran yang sangat penting dalam pembuatan aplikasi ini, karena data ini merupakan hal yang seharusnya menjadi daya tarik bagi user.
Dalam membuat data penulis menggunakan Unity, 3DS Max, dan Sketchup sebagai modeling 3D.

\subsection{Konsep dan Perencanaan Aplikasi}

Perancangan konsep berguna untuk memberikan beberapa solusi alternatif konsep penerapan Augmented Reality pada aplikasi simulasi ini kemudian di evaluasi berdasarkan persyaratan teknis, ekonomis, dan lain-lain. Tahapan ini diawali dengan mengenal dan menganalisa program. Hasil analisis spesifikasi aplikasi dilanjutkan dengan memetakan struktur fungsi komponen sehingga dapat disimpulkan beberapa solusi pemecahan masalah konsep aplikasi yang dikembangkan.

Dalam tahap ini konsep rancangan aplikasi penerapan Augmented Reality pada aplikasi pengenalan rumah adat indonesia adalah:

a. Menggunakan Augmented Reality sebagai teknologi yang akan dipadukan dalam aplikasi display masakan khas Sumbawa.

b. Menggunakan unity sebagai penerapan 3D modeling yang nantinya akan menjadi Augmented Reality.

c. Menggunakan aplikasi berbasis android yang nantinya akan dipadukan dengan augmented reality.

\section{PERANCANGAN SISTEM}

\subsection{Use Case}

Berikut ini merupakan use case pada aplikasi tutorial memasak masakan khas Sumbawa tersebut yang di tunjukkan pada Gambar 4.1

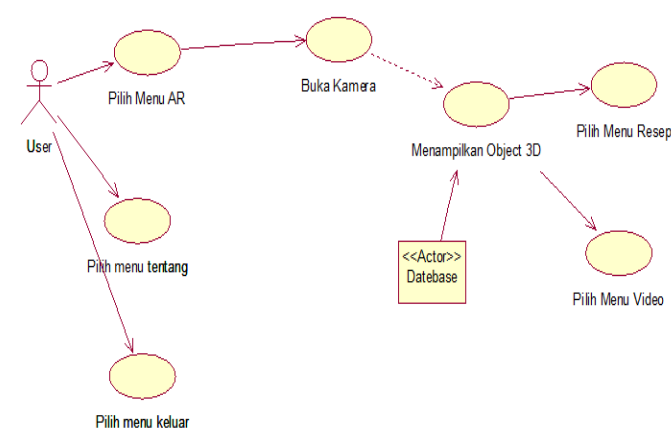

Gambar 4.1 Use Case Diagram

Penjelasan dari gambar 4.1 Use Case adalah: Dalam hal ini actor adalah user yang akan menggunakan aplikasi. User dapat memilih beberapa menu yang tersedia di aplikasi yaitu menu AR, menu petunujuk penggunaan, menu tentang, dan menu keluar. Dalam menu AR terdapat sub menu yaitu menu Resep masakan. 


\subsection{Aktivity Diagram}

Activity diagram dari aplikasi dapat dilihat pada Gambar 4.2

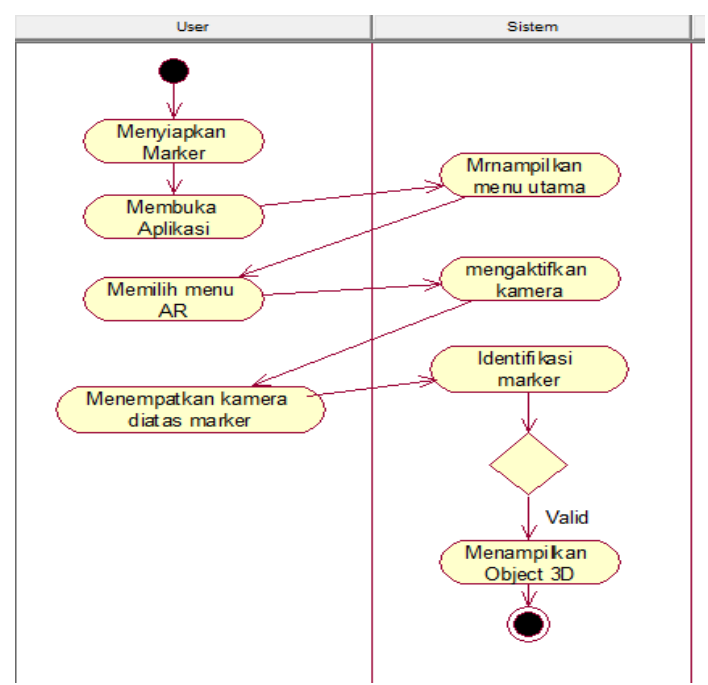

Gambar 4.2 Aktivity diagram.

Penjelasan dari gambar 4.2 aktivity diagram adalah : Dalam hal ini menjelaskan aktivitas user ketika menggunakan aplikasi. Ketika memulai menggunakan aplikasi user mulai menyiapkan marker, lalu membuka menu AR kemudian system akan mengaktifkan kamera dan user mulai menempatkan marker di atas kamera kemudian system akan menampilkan object 3D.

\section{HASIL DAN PEMBAHASAN}

\subsection{Tampilan Menu Utama}

Pada menu utama menampilkan pilihan sub menu, yaitu menu AR,tentang dan keluar yang mempunyai fungsi masing-asing.

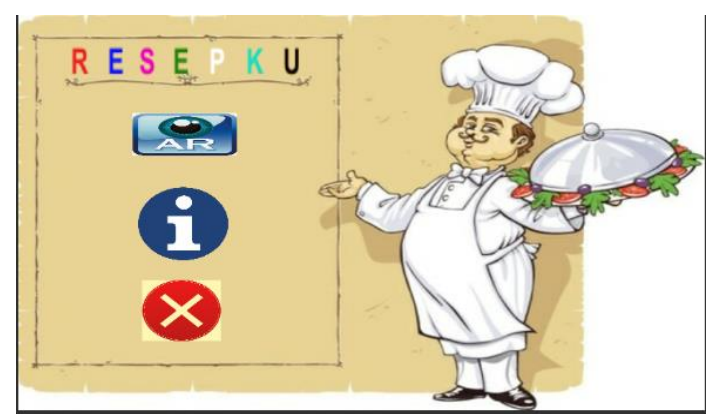

Gambar 5.1 Tampilan menu utama

\subsection{Tampilan Scan Marker}

Pada tampilan ini menunjukan hasil saat marker berhasil terdeteksi dan menampilkan objek 3D masakan sumbawa serta button resep masakan untuk melihat resep masakan itu sendiri.seperti pada Gambar 5.2.

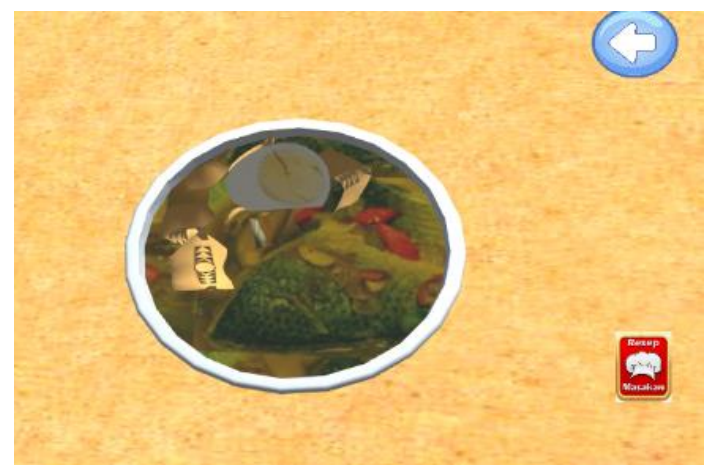

Gambar 5.2 Tampilan Scan Marker

\subsection{Tampilan Resep Masakan}

Pada tampilan ini menunjukkan hasil menu resep masakan dan menampilkan menu makanan Sumbawa seperti pada Gambar 5.3.

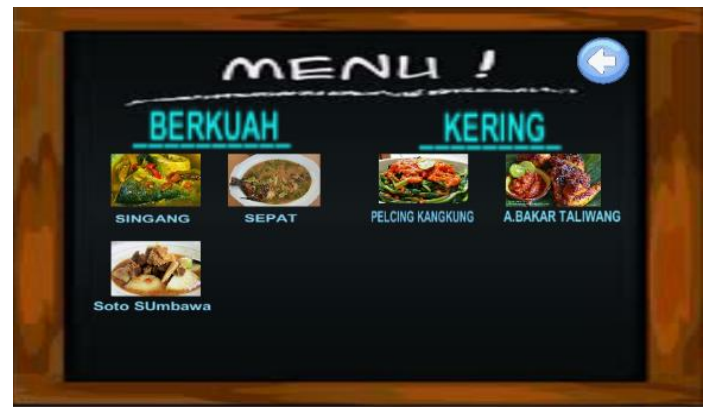

Gambar 5.3 Tampilan Menu resep masakan

\subsection{Pengujian Alpha}

Tahap pertama adalah pengujian Alpha yang dilakukan oleh penguji internal. Pengujian Alpha akan dinyatakan berhasil jika penguji internal menyatakan bahwa aplikasi berjalan dengan baik sehingga aplikasi yang dikembangkan dapat diuji ke tahap selanjutnya. Berikut adalah table 1, tabel pengujian Alpha. 
Tabel 1. Tabel Pengujian Alpha

\begin{tabular}{|c|c|c|c|c|}
\hline NO & Skenario & Hasil yang di harapkan & $\begin{array}{c}\text { Hasil } \\
\text { pengujian }\end{array}$ & Kesimpulan \\
\hline 1 & Install APK (Master) & $\begin{array}{l}\text { Proses instalasi berjalan dengan baik di } \\
\text { smartphone android }\end{array}$ & $\begin{array}{c}\text { Sesuai } \\
\text { harapan }\end{array}$ & Valid \\
\hline 2 & $\begin{array}{l}\text { Menjalankan aplikasi } \\
\text { yang terpasang }\end{array}$ & Aplikasi berkerja dan berjalan dengan baik & $\begin{array}{c}\text { Sesuai } \\
\text { harapan }\end{array}$ & Valid \\
\hline 3 & Pendeteksian marker & $\begin{array}{l}\text { Object penanda sesuai dengan penanda yang } \\
\text { disediakan }\end{array}$ & $\begin{array}{c}\text { Sesuai } \\
\text { harapan }\end{array}$ & Valid \\
\hline 4 & $\begin{array}{l}\text { Pendeteksian marker } \\
\text { untuk menampilkan } \\
\text { object dengan informasi } \\
\text { yang sesuai dengan } \text { object }\end{array}$ & $\begin{array}{l}\text { Camera smartphone dapat mengcapture } \\
\text { dengan baik pada marker dan object 3D dapat } \\
\text { tampil }\end{array}$ & $\begin{array}{c}\text { Sesuai } \\
\text { harapan }\end{array}$ & Valid \\
\hline 5 & Memilih menu AR & $\begin{array}{l}\text { Berpindah ke halaman yang sesuai dengan } \\
\text { pilihan dan masuk ke layar kamera untuk } \\
\text { aplikasi aughmented reality }\end{array}$ & $\begin{array}{l}\text { Sesuai } \\
\text { harapan }\end{array}$ & Valid \\
\hline 6 & $\begin{array}{l}\text { Memilih menu Button } \\
\text { resep masakan }\end{array}$ & $\begin{array}{l}\text { Berpindah ke halaman yang sesuai dengan } \\
\text { pilihan }\end{array}$ & $\begin{array}{c}\text { Sesuai } \\
\text { harapan }\end{array}$ & Valid \\
\hline 7 & Memilih Menu Masakan & Menanmpilkan resep masakan. & $\begin{array}{c}\text { Sesuai } \\
\text { harapan }\end{array}$ & Valid \\
\hline
\end{tabular}

\section{KESIMPULAN DAN SARAN}

\subsection{Kesimpulan}

Kesimpulan yang dapat diambil dari penelitian ini, sebagai berikut :

1. Aplikasi ini dapat menjadi sarana untuk memperkenalkan masakan khas Sumbawa.

2. Aplikasi dapat berjalan dengan baik sesuai perancangan sebelumnya.

3. Interaksi menggunakan tombol pada aplikasi ini memudahkan user untuk menjalankan aplikasi.

4. Sudut dan jarak kamera saat mengidentifikasi marker sangat berpengaruh pada proses tracking objek

\subsection{Saran}

Saran yang dapat dijadikan untuk mengembangkan aplikasi ini, sebagai berikut :

1. Kedepannya dapat melakukan scan tanpa harus mencetak marker menggunakan metode Markless AR.

2. Dapat membuat aplikasi AR tentang masakan daerah yang lain untuk lebih mengenalkan kuliner indonesia.

\section{DAFTAR PUSTAKA}

[1] Pratikno Heri. Kontrol Gerakan Objek 3D Augmented Reality Berbasis Titik Fitur Wajah dengan POSIT. JNTETI, Vol. 4, No.1. $2301-4156$.

[2] Saurina Nia. Pengembangan Media Pembelajaran Untuk Anak Usia Dini Menggunakan Augmented Reality. Jurnal IPTEK Vol.20 No.1. 1411-7010.

[3] Wahyudi Andria Kusuma. ARca, Pengembangan Buku Interaktif Berbasis Augmented Reality dengan Smartphone Android. JNTETI Vol. 3 No. 2. 2301 4156

[4] Permana Fitri Yuliantri. Mempertahankan Pasar Media Cetak Melalui Konten Augmented Reality/AR. Channel, Vol. 5, No. 2. 23389176

[5] Ramdhan Khemal Rizky, Nurhasanah Youllia Indrawaty, Utoro Rio Korio. Aplikasi Media Pembelajaran Tulang Manusia Menggunakan Augmented Reality (AR) Berbasis Android. Jurnal Teknik Informatika dan Sistem Informasi Vol. 3 No.3. 2443-2229. 